\title{
Effect of Water Salinity on the Spatial Variability of Soil and Plant Parameters
}

\author{
Ali Ajeel ${ }^{1,2}$, Ali Saeed ${ }^{1,2}$, Giovanna Dragonetti ${ }^{1}$, Alessandro Comegna ${ }^{2}$, Nicola Lamaddalena $^{1}$ and Antonio \\ Coppola $^{2}$ \\ 1. Mediterranean Agronomic Institute, Land and Water Division, IAMB, Bari 70010, Italy \\ 2. School of Agricultural Forestry Food and Environmental Sciences (SAFE), University of Basilicata, Potenza 85100, Italy
}

\begin{abstract}
Spatial pattern and interdependence of different soil and plant parameters were examined in green bean field experiment carried out at the Mediterranean Agronomic Institute of Bari (MAIB), Italy. The study aimed to identify the spatial distribution of soil and plant parameters and their relationship at transects scale. The experiment consisted of three transects of $30 \mathrm{~m}$ length and 4.2 $\mathrm{m}$ width, irrigated with three different salinity levels $\left(1 \mathrm{dSm}^{-1}, 3 \mathrm{dSm}^{-1}, 6 \mathrm{dSm}^{-1}\right)$. Soil measurements (electrical conductivity and soil water content) were monitored along each transect in 24 sites, using TDR probe installed vertically at soil surface. Water storage was measured by using Diviner sensor for calculating directly the evapotranspiration fluxes along the whole soil profile under the different salinity levels imposed during the experiment. In the same 24 sites, crop monitoring involved measurements of Leaf Area Index (LAI), Osmotic Potential (OP), Root length Density (RID) and Evapotranspiration fluxes (ET). Soil and plant properties were analyzed using both classical and geostatistical methods which included descriptive statistics, semivariograms and cross-semivariograms. Results indicated that moderate to large spatial variability existed across the field for soil and plant parameters, especially under the $6 \mathrm{dSm}^{-1}$ salinity treatment. A relatively satisfactory fit of the experimental cross-semivariogram was obtained for the $6 \mathrm{dS}^{-1}$, thus indicating similar spatial structures of the pairs of compared variables. By contrast, the experimental cross-semivariograms observed under the $3 \mathrm{dS}^{-1}$ treatment indicated no significant correlation structure between the compared variables. Overall, the results observed in the $3 \mathrm{dSm}^{-1}$ were not significantly different from those obtained in the $1 \mathrm{dSm}^{-1}$ transect and suggested a general insensitivity of the crop response to those levels of salinity.
\end{abstract}

Key words: Soil and crop properties, spatial variability, semivariogram, cross-semivariogram.

\section{Introduction}

Salinity is a major problem in agriculture sector in arid and semiarid regions. The accumulation of salts over time in the root zone limits the water uptake of plants by reducing the osmotic potential and thus the total soil water potential [1-3]. Salinity is rarely uniform with depth and usually varies with time at field scale. The soil physical and chemical factors such as soil texture, water content and salinity distribution in the soil profile are the most dominant influences on yield and growth variability [4].

Salinity has been extensively reported to have

Corresponding author: Ali Ajeel, Ph.D. student, research field: plant physiology and solute transport. E-mail: ali_alheetimi@yahoo.com. negative impacts on the majority of arable crops and classified them as sensitive, moderately sensitive and high sensitive crops [2]. Many laboratory and field experiments have been conducted to evaluate crop salt tolerance under uniform salinity along the soil profile. Comprehensive reviews of such studies are well documented $[5,6]$. However, salinity is rarely uniform in space on both the vertical and the horizontal direction. The spatial variability of soil salinity with water content has shown dominant effects on crop yield variability $[4,7]$. However, the effects of soil salinity on the physiological crop parameters and their spatial variation across field still require depth analysis. Spatial variation of various soil and plant properties may be was studied by using classical statistics and geostatistics intensively. Geostatistics may provide 
useful information for assessing spatial variability of soil properties and has increasingly been used by soil scientists and researchers in recent years [8, 9].

Semivariograms and cross-semivariograms have been used to characterize and model spatial variance of data to assess how data points are related with separation distances. There are many studies in the literature on the use of geostatistic analysis to describe the spatial variability of single soil properties [8-12]. However, rarely these studies have reported information on the spatial variability of soil parameters (i.e., water content and electrical conductivity) and the corresponding variability on plant growth at field scale under different water salinity levels. Therefore, the objectives of this study were to apply geostatistics approach to characterize field scale spatial variability of selected soil-plant properties and to explore the spatial interdependence between soil-plant parameters using cross-semivariogram analysis.

\section{Materials and Methods}

The experiment was carried out at the research station of MAIB in 2013 south-east of Italy. The soil was pedologically classified as Colluvic Regosol, consisting of a silty loam layer of an average depth of $70 \mathrm{~cm}$ on a fractured calcarenite rock. The experiment consisted of three transects of $30 \mathrm{~m}$ length and $4.2 \mathrm{~m}$ width, equipped with a drip irrigation system, consisting of fourteen dripper lines at $35 \mathrm{~cm}$ distance and a distance among drippers along each line of 20 $\mathrm{cm}$, with dripper discharge of $2 \mathrm{~L} / \mathrm{h}$. The transects were irrigated with three different salinity levels (1 $\mathrm{dSm}^{-1}, 3 \mathrm{dSm}^{-1}, 6 \mathrm{dSm}^{-1}$ ) by using calcium chloride $\left(\mathrm{CaCl}_{2}\right)$. Each transect consisted of seven rows of green beans crop, $70 \mathrm{~cm}$ apart and plants in each row $40 \mathrm{~cm}$ apart. The irrigation volumes were calculated according to the water storage measured by a Diviner 2000 sensor. Twenty-four access tubes were installed along the middle line of each transect at $60 \mathrm{~cm}$ depth to monitor soil water content using Diviner 2000 sensor. Diviner readings were taken at $10 \mathrm{~cm}$ depth intervals up to $60 \mathrm{~cm}$ just before and two hours after every irrigation applications. The difference between water storage at field capacity and the storage measured just before irrigation allowed calculating the irrigation volumes to bring the soil water content in the root zone to the field capacity. The apparent electrical conductivity was monitored during the growing season by inserting a TDR probe vertically at the soil surface in 24 sites along the middle line of each transect. Furthermore, plant measurements (e.g., Leaf area index, Transpiration rate, Root length density, Osmotic potential and yield) were carried out to evaluate the physiological state of plants, on the same 24 sites already identified for soil measurements. As crop responses to salinity depend on the electrical conductivity of soil solution (ECw), a calibration procedure of TDR was also requested for translating $\mathrm{ECb}$ values measured by TDR to the corresponding $\mathrm{ECw}$ values. In this study, TDR probe calibration was carried out in the laboratory according to the procedure [14]. Geostatistical analysis, including semivariogram, cross-semivariogram model fitting procedures, were carried out using $\mathrm{GS}^{+}$(Gamma Design Software, 2004, Geostatistics for the Environmental Sciences, St. Plainwell, Mich.) to evaluate the degree of spatial variability of soil and plant parameters.

\section{Results and Discussion}

Table 1 shows the summary of the statistics of the measured soil and plant parameters. The coefficient of variation $(\mathrm{CV})$ values of measured soil and plant properties in the three different treatments ranged between $29.29 \%$ for electrical conductivity of soil solution (ECW) and $7.17 \%$ for soil water content $(\theta)$ in the transect treated at $1 \mathrm{dS}^{-1}$. The standard deviation (SD) of all parameters exhibited the highest values in transect treated with $6 \mathrm{dS}^{-1}$ saline water, except in the case of LAI. Moreover, the soil and plant data were all normally distributed (with a skewness between 1 and -2) 
Table 1 Summery statistic for selected soil and plant parameters.

\begin{tabular}{|c|c|c|c|c|c|c|c|}
\hline $\begin{array}{l}\text { Soil and plant } \\
\text { parameters }\end{array}$ & Mean & Min & Max & CV\% & SD & Skewness & Kurtosis \\
\hline $\mathrm{ECw}-1 \mathrm{dS}^{-1}$ & 2.35 & 0.87 & 3.69 & 29.29 & 0.69 & -0.41 & -0.33 \\
\hline $\mathrm{ECw}-3 \mathrm{dS}^{-1}$ & 5.25 & 3.77 & 7.07 & 13.98 & 0.73 & 0.16 & 0.85 \\
\hline $\mathrm{ECw}-6 \mathrm{dS}^{-1}$ & 6.26 & 1.64 & 8.26 & 23.67 & 1.48 & -1.36 & 2.12 \\
\hline$\theta-1 \mathrm{dS}^{-1}$ & 0.25 & 0.22 & 0.29 & 7.17 & 0.02 & 0.36 & -0.73 \\
\hline$\theta-3 \mathrm{dS}^{-1}$ & 0.22 & 0.20 & 0.27 & 7.86 & 0.02 & 0.75 & 0 \\
\hline$\theta-6 \mathrm{dS}^{-1}$ & 0.22 & 0.20 & 0.27 & 11.06 & 0.03 & 0.44 & -1.21 \\
\hline ET-1 dS $\mathrm{S}^{-1}$ & 0.51 & 0.36 & 0.73 & 20.58 & 0.10 & 0.61 & -0.53 \\
\hline ET-3 dS ${ }^{-1}$ & 0.53 & 0.33 & 0.76 & 22.51 & 0.12 & 0.41 & -0.80 \\
\hline ET-6 dS ${ }^{-1}$ & 0.48 & 0.27 & 0.75 & 26.99 & 0.13 & 0.25 & -1.02 \\
\hline LAI- $1 \mathrm{dS}^{-1}$ & 0.63 & 0.35 & 0.91 & 25.19 & 0.16 & 0.17 & -0.78 \\
\hline LAI-3 dS ${ }^{-1}$ & 0.66 & 0.35 & 0.99 & 22.14 & 0.15 & 0.47 & 0.74 \\
\hline LAI- $6 \mathrm{dS}^{-1}$ & 0.52 & 0.29 & 0.68 & 18.23 & 0.10 & -0.23 & -0.79 \\
\hline OP-1 $\mathrm{dS}^{-1}$ & 0.91 & 0.78 & 1.12 & 9.18 & 0.08 & 0.81 & -0.18 \\
\hline OP-3 $\mathrm{dS}^{-1}$ & 1.04 & 0.74 & 1.51 & 15.18 & 0.16 & 0.84 & -0.22 \\
\hline OP-6 $\mathrm{dS}^{-1}$ & 1.15 & 0.82 & 1.39 & 13.73 & 0.16 & -0.34 & -0.83 \\
\hline RID-1 dS ${ }^{-1}$ & 0.52 & 0.29 & 0.68 & 18.23 & 0.10 & -0.23 & -0.18 \\
\hline RID-3 dS ${ }^{-1}$ & 2.14 & 1.28 & 2.65 & 18.17 & 0.39 & -0.75 & -0.22 \\
\hline RID-6 dS ${ }^{-1}$ & 1.84 & 1.13 & 2.56 & 21.06 & 0.39 & 0.01 & -0.83 \\
\hline
\end{tabular}

and therefore no transformation was used for geostatistical analysis. The semivariograms calculated for soil and plant data (ECW, $\theta, \mathrm{ET}, \mathrm{LAI}, \mathrm{OP}, \mathrm{RID})$ are depicted in (Fig. 1).

Semivariogram coefficients for each soil plant parameters with the best fitted model are listed in table 2 . The $\mathrm{R}^{2}$ values in table 2 show that models fit the experimental field semivariogram data very well for soil parameters (ECw, $\theta)$, as well as for evapotranspiration (ET) in transects treated with 1 $\mathrm{dS}^{-1}$ and $6 \mathrm{dS}^{-1}$. Simultaneously, the Residual Sum of Squares (RSS) values were very small for semivariogram models of soil and plant parameters monitored in this study, except for $\mathrm{ECw}$. The ratio between nugget $\left(\mathrm{C}_{0}\right)$ and sill $\left(\mathrm{C}_{0}+\mathrm{C}\right)$ (the so called nugget ratio) was calculated for soil and plant properties and used to investigate the degree of spatial dependence across the experimental field. Many authors reported that if the nugget ratio is $\leq 0.25$, the variable should be considered to be strongly spatially dependent; if the nugget ratio lies in the range between 26 and $75 \%$ the variable has to be considered moderately spatially dependent; finally, if the nugget ratio is greater than $75 \%$, the variable has to be considered weakly spatially dependent $[9,10,12,13]$. From the values of nugget ratio for the semivariograms in (Fig. 1), it seems that that there is moderate spatial dependence of $\mathrm{ECw}$ and $\mathrm{ET}$ at transects treated $1 \mathrm{dS}^{-1}$ and $3 \mathrm{dS}^{-1}$. Also, a moderate spatial dependence was found for $\theta$ in the transect treated with $1 \mathrm{dS}^{-1}$. On the contrary, the nugget ratio for the other soil and plant parameters indicated weakly spatial dependence in all the three transects (Table 2).

The graphs in (Fig. 2) (A, B, C and D) depict the cross-semivariograms calculated for selected pairs of soil and plant parameters (ECw vs. RLD and ET) in the $3 \mathrm{dS}^{-1}$ and $6 \mathrm{dS}^{-1}$ salinity treatments. Cross-semivariograms were calculated to identify any possible effects of soil salinity and its affect on the root length density and evapotranspiration fluxes, as well as their spatial interdependence. In this study different theoretical cross-semivariogram models have been used (namely Gaussian, Exponential and Spherical). Table 3 depicts the parameters obtained for each of the model used. 

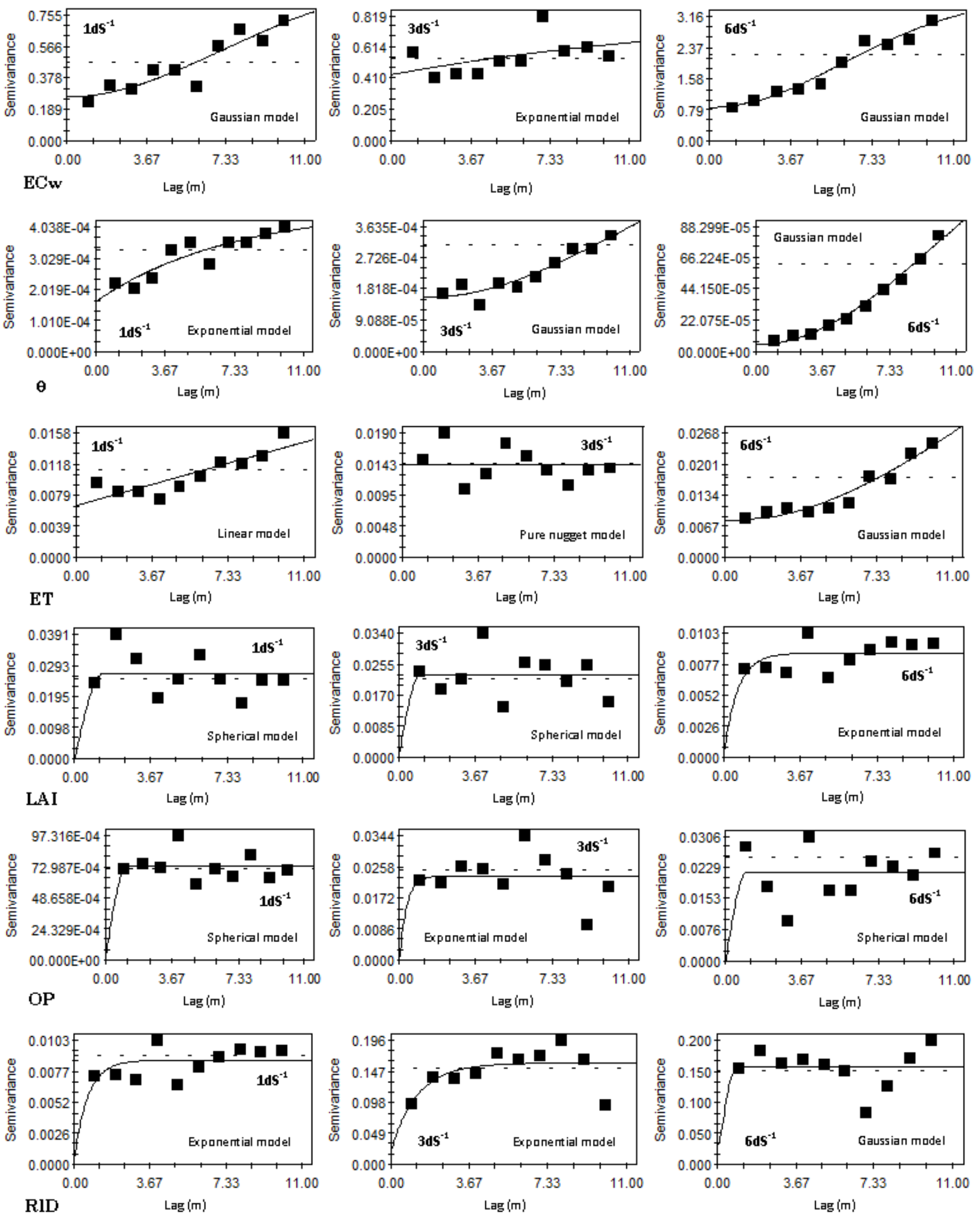

Fig. 1 Semivariogram models of soil and plant parameters. 
Table 2 Coefficients of the theoretical semivariogram model of soil and plant parameters.

\begin{tabular}{|c|c|c|c|c|c|c|c|}
\hline $\begin{array}{l}\text { Soil and plant } \\
\text { parameters }\end{array}$ & Model & Nugget, $\mathrm{C}_{0}$ & Sill, $C_{0}+C$ & $\begin{array}{l}\text { Nugget Ratio } \\
\mathrm{C}_{0} /\left(\mathrm{C}_{0}+\mathrm{C}\right)\end{array}$ & Range A (m) & $\mathrm{RSS}^{[\mathrm{a}]}$ & $\mathrm{R}^{2}$ \\
\hline $\mathrm{ECw}-1 \mathrm{dS}^{-1}$ & Gaussian & 0.264 & 0.968 & 0.727 & 10.06 & 0.0400 & 0.84 \\
\hline $\mathrm{ECw}-3 \mathrm{dS}^{-1}$ & Exponential & 0.433 & 0.868 & 0.501 & 17.04 & 0.0942 & 0.23 \\
\hline $\mathrm{ECw}-6 \mathrm{dS}^{-1}$ & Gaussian & 0.839 & 3.657 & 0.771 & 8.36 & 0.191 & 0.96 \\
\hline$\theta-1 \mathrm{dS}^{-1}$ & Exponential & 0.00017 & 0.00046 & 0.642 & 7.07 & $7.289 * 10^{-9}$ & 0.82 \\
\hline$\theta-3 \mathrm{dS}^{-1}$ & Gaussian & 0.00016 & 0.00070 & 0.777 & 15.87 & $3.734 * 10^{-9}$ & 0.90 \\
\hline$\theta-6 \mathrm{dS}^{-1}$ & Gaussian & 0.00005 & 0.00210 & 0.976 & 15.25 & $7.458 * 10^{-9}$ & 0.98 \\
\hline ET- $1 \mathrm{dS}^{-1}$ & Linear & 0.00662 & 0.01387 & 0.523 & 10 & $1.535 * 10^{-5}$ & 0.73 \\
\hline ET-3 dS ${ }^{-1}$ & Pure nugget & 0.01423 & 0.01423 & 1 & 10 & $6.247 * 10^{-5}$ & 0 \\
\hline ET-6 dS ${ }^{-1}$ & Gaussian & 0.00790 & 0.07870 & 0.9 & 19.71 & $1.767 * 10^{-5}$ & 0.93 \\
\hline LAI-1 dS ${ }^{-1}$ & Spherical & 0.00003 & 0.02676 & 0.999 & 1.36 & $3.552 * 10^{-4}$ & 0.01 \\
\hline LAI-3 $\mathrm{dS}^{-1}$ & Spherical & 0.00176 & 0.02252 & 0.922 & 1 & $3.052 * 10^{-4}$ & 0 \\
\hline LAI- $6 \mathrm{dS}^{-1}$ & Exponential & 0.00074 & 0.00868 & 0.915 & 0.68 & $1.211 * 10^{-5}$ & 0.14 \\
\hline OP-1 dS ${ }^{-1}$ & Spherical & 0.00045 & 0.00734 & 0.939 & 1.13 & $9.898 * 10^{-6}$ & 0 \\
\hline OP-3 $\mathrm{dS}^{-1}$ & Exponential & 0.00092 & 0.02344 & 0.939 & 0.36 & $3.437 * 10^{-4}$ & 0 \\
\hline OP-6 $\mathrm{dS}^{-1}$ & Spherical & 0.00001 & 0.02172 & 1 & 1 & $3.444 * 10^{-4}$ & 0 \\
\hline RID-1 dS ${ }^{-1}$ & Exponential & 0.00074 & 0.00868 & 1 & 0.68 & $1.211 * 10^{-5}$ & 0.14 \\
\hline RID-3 dS ${ }^{-1}$ & Exponential & 0.02050 & 0.16000 & 0.872 & 1.24 & $6.446 * 10^{-3}$ & 0.36 \\
\hline RID-6 $\mathrm{dS}^{-1}$ & Gaussian & 0.03150 & 0.15700 & 0.799 & 0.47 & $9.066 * 10^{-3}$ & 0 \\
\hline
\end{tabular}

[a] RSS is the residual sums of squares for the theoretical semivariogram models.
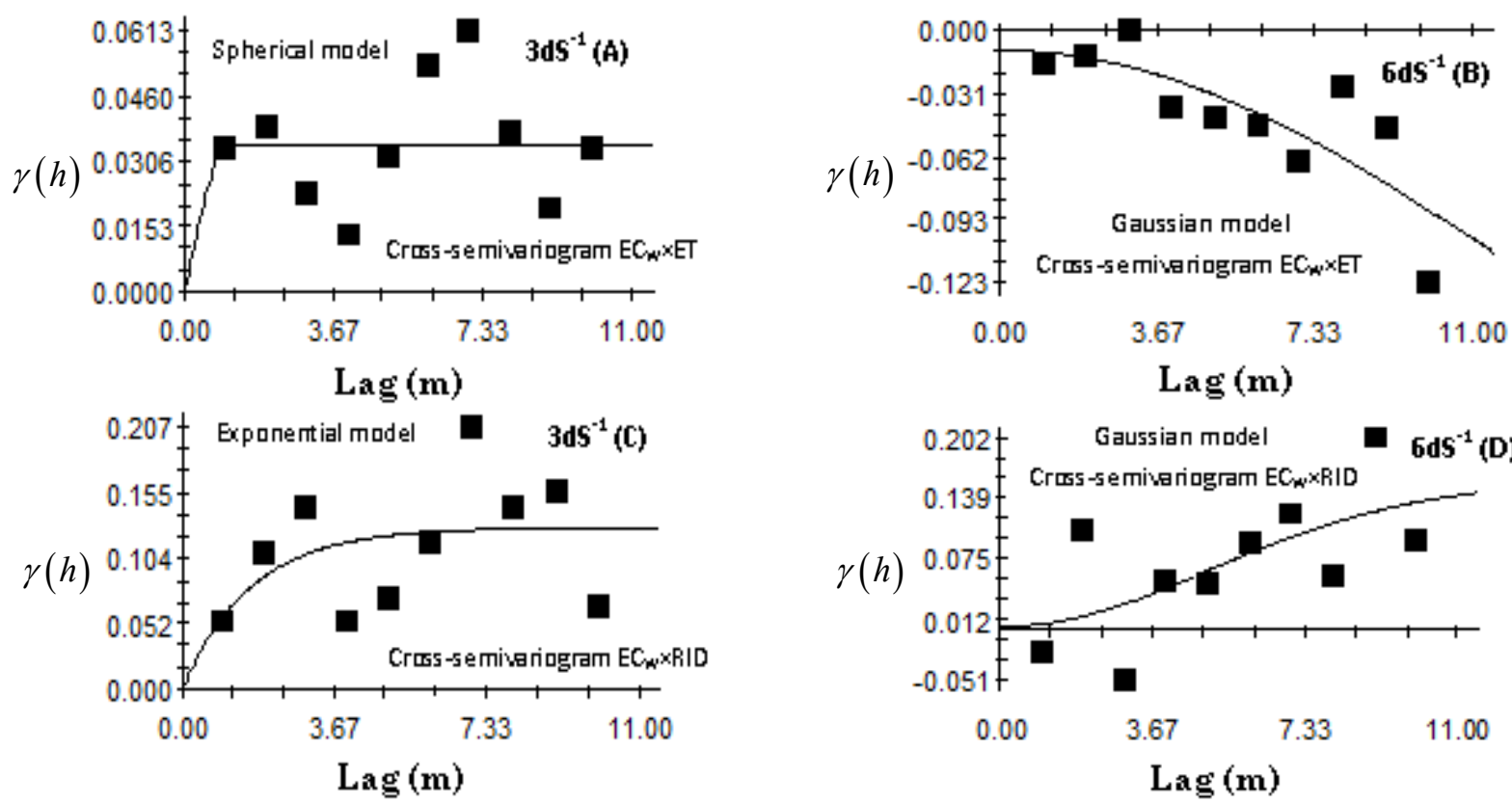

Fig. 2 Cross-semivariogram models of selected soil and plant parameters.

According to the $\mathrm{R} 2$ values, a relatively good fit of the experimental cross-semivariogram was obtained for all the cases at $6 \mathrm{dS}^{-1}$, thus indicating similar spatial structures of the pairs of compared variables. By contrast, the corresponding values for the $3 \mathrm{dS}^{-1}$ treatment indicate an unsatisfactory fit and thus no significant correlation structure between the compared variables. Overall, the results observed in the $3 \mathrm{dSm}^{-1}$ were not significantly different from those obtained in the $1 \mathrm{dSm}^{-1}$ transect (data not shown), and suggested a general insensitivity of the crop response to those levels of salinity. As for the $6 \mathrm{dSm}^{-1}$ treatment, 
Table 3 Coefficients of the theoretical cross-semivariogram model of soil and plant parameters.

\begin{tabular}{llllllll}
\hline $\begin{array}{l}\text { Soil and plant } \\
\text { parameters }\end{array}$ & \multirow{2}{*}{ Model } & $\begin{array}{l}\text { Nugget, } \\
\mathrm{C}_{0}\end{array}$ & Sill, $\mathrm{C}_{0}+\mathrm{C}$ & $\begin{array}{l}\text { Nugget Ratio } \\
\mathrm{C}_{0} /\left(\mathrm{C}_{0}+\mathrm{C}\right)\end{array}$ & Range A $(\mathrm{m})$ & RSS $^{[\mathrm{a}]}$ & $\mathrm{R}^{2}$ \\
\hline $\mathrm{ECw} \times \mathrm{ET} 3 \mathrm{dS}^{-1}$ & Spherical & 0.00010 & 0.03490 & 0.00286 & 1.12 & $1.905^{*} 10^{-3}$ & 0.10 \\
$\mathrm{ECw} \times \mathrm{ET} 6 \mathrm{dS}^{-1}$ & Gaussian & -0.01000 & -0.32700 & 0.03058 & 18.79 & $4.104 * 10^{-3}$ & 0.61 \\
$\mathrm{ECw} \times \mathrm{RID} 3 \mathrm{dS}^{-1}$ & Exponential & 0.00010 & 0.12820 & 0.00078 & 1.66 & 0.0191 & 0.17 \\
$\mathrm{ECw} \times \mathrm{RID} 6 \mathrm{dS}^{-1}$ & Gaussian & 0.00270 & 0.15540 & 0.01737 & 7.13 & 0.0269 & 0.42 \\
\hline
\end{tabular}

[a] RSS is the residual sums of squares for the theoretical semivariogram models.

according to the criteria [13] to evaluate cross-correlation between two variables, the cross-semivariograms of the (Fig. 2) suggest positive spatial interdependence at all lags except the lag $=1$ and $3(\mathrm{ECW} \times \mathrm{RID})$. On the contrary, a negative spatial interdependence was observed between electrical conductivity of soil solution ECW and ET (Fig. 2B). These conflict results of spatial interdependence between some soil and plant parameters might be related with the dynamic of salt and water in the soil profile.

\section{Conclusions}

The spatial variability and the interdependence between different soil and plant parameters were explored at transect scale under three different salinity applications by using classical statistics and geostatistical approaches. The results from both the approaches indicated that moderate to large spatial variability existed in this study across the field for soil and plant parameters especially under the $6 \mathrm{dSm}^{-1}$ salinity treatment. In general, the statistical approach used proved helpful to establish the relationship between the spatial distribution of soil water salinity and the corresponding variability of effects on canopy development and yield indices of bean based on different soil and crop sensors. Field scale variability of soil salinity and crop response have been generally approached by classical randomized blocks schemes allowing for calculating the main statistics of that response as related to the average and variance of soil salinity. By contrast, our study used close monitoring sites along continuous extended transects rather than randomized blocks. This way, the spatial variability of the relationship soil salinity-crop response were analyzed continuously in the space and the spatial correlation (which cannot be observed in randomized blocks) can be used as an additional and important information for understanding the mechanisms of plant response to salinity.

\section{References}

[1] Shannon, M. C., Grieve, C. M., and Francois, L. E. 1994. "Whole-plant Response to Salinity. In: Wilkinson R. E. (ed)." Plant Environment Interactions: 199-244.

[2] Sheldon, A., Menzies, N., So, H., and Dalal, R. 2004. "The Effect of Salinity on Plant Available Water." In: (eds). Proceedings for the SuperSoil 2004 Conference'. The University of Sydney, NSW.(Ed. B. Singh)(The Regional Institute: Gosford, NSW).

[3] Corwin, D. L., and Lesch, S. M. 2005. "Apparent Soil Electrical Conductivity Measurements in Agriculture." Computers and Electronics in Agriculture 46 (1-3): 11-43. doi.org/10.1016/j.compag.2004.10.005.

[4] Dixit, P. N., and Deli, C. 2010. "Impact of Spatially Variable Soil Salinity on Crop Physiological Properties, Soil Water Content and yield of Wheat in a Semi Arid Environment." Australian Journal of Agricultural Engineering 1 (3): 93-100.

[5] Maas, E. V., and Hoffman, G. J. 1977. "Crop Salt Tolerance-current Assessment." Irrigation and Drainage Division 103: 115-34.

[6] Maas, E. V. 1993. "Testing Crops for Salinity Tolerance." Proceedings of the Workshop on adaptation of plants to soil stresses, 1-4 August 1993, University of Nebraska, Lincoln, NE, USA.: 234-47.

[7] Coppola, A., Chaali, N., Dragonetti, G., Lamaddalena, N., and Comegna, A. 2014. "Root Uptake under Non-uniform Root-zone Salinity." Ecohydrology.

[8] Jabro, J., Stevens, W., Evans, R., and Iversen, W. 2010. "Spatial Variability and Correlation of Selected Soil Properties in the Ap Horizon of a CRP Grassland." American Society of Agricultural and Biological Engineers 26 (3).

[9] Jabro, J. D., Stevens, B. W., and Evans, R. G. 2006. 
"Spatial Relationships among Soil Physical Properties in a Grass-alfalfa Hay Field." Soil Science 171 (9): 719-27.

[10] López-Granados, F., Jurado-Expósito, M., Atenciano, S., García-Ferrer, A., de la Orden, M. S., and García-Torres, L. 2002. "Spatial Variability of Agricultural Soil Parameters in Southern Spain." Plant and Soil 246 (1): 97-105.

[11] Yang, F., Zhang, G., Yin, X., and Liu, Z. 2011. "Field-scale Spatial Variation of Saline-sodic Soil and Its Relation with Environmental Factors in Western Songnen Plain of China." International Journal of Environmental Research and Public Health 8 (2): 374-87.

[12] Fathi, H., Fathi, H., and Moradi, H. 2014. "Spatial
Variability of Soil Characteristic for Evaluation of Agricultural Potential in Iran." Merit Research Journal of Agricultural Science and Soil Sciences 2 (2350-2274): 24-31.

[13] Cambardella, C., Moorman, T., Parkin, T., Karlen, D., Novak, J., Turco, R., and Konopka, A. 1994. "Field-scale Variability of Soil Properties in Central Iowa Soils." Soil Science Society of America Journal 58 (5): 1501-11.

[14] Mallants, D., Vanclooster, M., Vanderborght, J., Feyen, J., Toride, N., and van Genuchten, M. T. 1996. "Comparison of Three Methods to Calibrate TDR for Monitoring Solute Movement in Undisturbed Soil." Soil Science Society America Journal 60 (3): 747-54. doi.org/10.2136/sssaj1996.03615995006000030010x. 